\title{
“Espacio público y espacio privado. Miradas desde el sexo y el género"
}

\author{
"Public Space and Private Space. \\ Looks on Sex and Gender"
}

\author{
Reseñado por Juan Fernando Báez Monsalve* \\ Universidad Industrial de Santander, Colombia
}

Recibida: 15 de febrero de 2019. Aprobada: 23 de abril de 2019.

10.25100/lamanzanadeladiscordia.v14i1.8065

Reseña

Palabras clave: Mujeres; género; espacio público; espacio privado; feminismo.

Keywords: Women; gender; public space; private space; feminism.

Reseña del libro: Hernández, Elena (Ed.). (2016). Espacio público y espacio privado. Miradas desde el sexo y el género. Madrid: Abada Editores.

Elena Hernández Sandoica es licenciada en filosofia y letras de la Universidad Complutense de Madrid. Doctora en historia por la misma universidad. Desde 1999, trabaja como docente de la UCM en la cátedra de Historia Contemporánea. Se ha interesado por temas como los movimientos sociales, el feminismo, la historia de las mujeres y la historiografía. Es autora de varios libros, entre ellos Historia de la historiografia feminista $y$ de las mujeres, Tendencias historiográficas e Historia de la política colonial.

Figura 1. Carátula del libro "Espacio público y espacio privado. Miradas desde el sexo y el género" de Elena Hernández Sandoica

Fuente: https://abadaeditores.com/historia/espacio-publicoy-espacio-privado-miradas-desde-el-sexo-y-el-genero-.html
ELENA HERNÁNDEZ SANDOICA

(ED.)

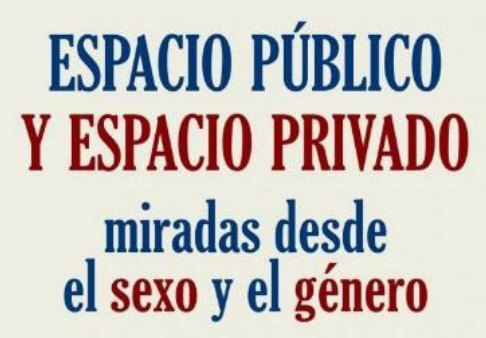

(2iv)

A B A D A E D I TORES

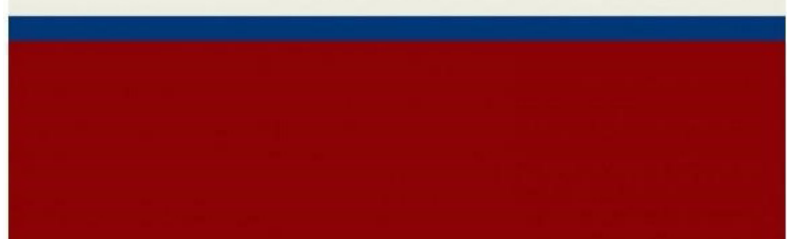

* Historiador de la Universidad Industrial de Santander. Se ha interesado por los estudios de género y por los estudios y el movimiento LGBTI en Colombia. Coautor del artículo Manuales de urbanidad en la Colombia del siglo XIX: Modernidad, Pedagogía y Cuerpo (2015) y autor de Homosexualidad y prensa: Vanguardia Liberal, Bucaramanga (1991 - 2007) (2018). Ha escrito, también, algunas reseñas para revistas académicas en Colombia. Miembro activo de la Asociación Plataforma LGBTIQ Santander y del grupo de investigación Historia, Archivística y Redes de Investigación. Correo electrónico: ferbm23@gmail.com ORCID: 0000-0001-9421-0815 
Los espacios privados y públicos y su relación con las mujeres han sido uno de los temas centrales del pensamiento feminista. Desde las primeras sufragistas, e incluso desde el siglo XVIII, la idea de la mujer como sujeta incorporada a los espacios privados y negada a los públicos por el patriarcado y el capitalismo, ha sido una de las banderas de lucha feminista, en cuanto la opresión que ha significado la reclusión de las mujeres en la casa, en la maternidad y en el matrimonio. Lo anterior al estar históricamente relegadas de la ciudadanía real, de la educación, de los centros de toma de decisiones políticas y de la calle misma. Por esta razón, Espacio público y espacio privado. Miradas sobre el sexo y el género editado por Elena Hernández Sandoica, se adentra en conocer y reconocer, desde el contexto español y europeo, cómo las mujeres han estado presentes en diferentes espacios públicos y cómo lo público y lo privado se entremezclan en posturas, ideologías, maneras, pensamientos y acciones que constituyen a las mujeres mismas como agentes sociales y como sujetas políticas.

El libro comienza con el texto de María Ramos titulado Las palabras y experiencias de Irene. Las mujeres y la construcción de la paz [1868-1918]. Este apartado hace un recorrido por los grupos pacifistas de mujeres durante la segunda mitad del siglo XIX y primeros años del XX en España, en el que expone que la idea de la mujer-cuidadora, como esencia de la feminidad y que la encierra en los espacios privados, no tiene correspondencia con la realidad, especialmente en contextos de guerra. Al respecto, explica que las mujeres pacifistas conformaron asociaciones que poseyeron un rol activo en la consecución de derechos no solo para las mismas mujeres, sino también para otros sectores poblacionales. Así, las mujeres españolas feministas y pacifistas decimonónicas, inspiradas por la Tercera República Francesa, el laicismo, el racionalismo, y desde diversas posturas ideológicas, conformaron un frente de oposición a las guerras colonialistas en los últimos territorios dominados por España en América y en África del norte. Los movimientos pacifistas de mujeres, de acuerdo con la autora, se alimentaron constantemente de las ideas anarquistas y socialistas, por lo que realizaban una crítica mordaz a los principios y a las tradiciones de la familia burguesa, mientras denunciaban el militarismo, el imperialismo y la guerra, contraponiéndolos al amor libre y a la maternidad consciente. Por eso, el pacifismo de los grupos de mujeres, de acuerdo con Ramos, no puede entenderse como una condición pasiva y privada, sino activa y pública, que se reflejó también en la experiencia de muchas mujeres durante la Primera Guerra Mundial.

El segundo capítulo, Formulaciones discursivas y género: una aproximación a las identidades y sujetos nacionales en Galicia (1910-1936), escrito por Paula Pérez, relata cómo el nacionalismo gallego y el feminismo sufragista fueron muy cercanos en Galicia y cómo esta relación determinó en buena medida las características y particularidades del feminismo gallego: la idea de construir una nación gallega independiente y soberana suponía la necesidad de producir y reproducir ciudadanos para la Nación. Esto significó que el feminismo gallego sufragista mantuviera entre sus principios la conexión mujer/madre como agentes clave del proceso social nacionalista. Esta concepción de las mujeres y la feminidad por parte de los grupos feministas se mantuvo porque el feminismo sufragista nunca fue fuerte en la región, al igual que los movimientos obreros, por lo que el nacionalismo gallego tuvo una base conservadora importante y predominante. Las costumbres, la historia y las tradiciones se convirtieron, pues, en los referentes del movimiento nacionalista, en los que las mujeres poseían un rol igualmente tradicionalista, aunque, como apunta la autora, tampoco desde una perspectiva reduccionista de "mero aparato reproductivo". Estos discursos, de todas maneras, convivieron con retóricas liberales y de izquierda que tenían fuertes repercusiones en las mujeres obreras gallegas, en especial por la migración mayormente de hombres al extranjero, que supuso la entrada de las mujeres a las fábricas y a espacios laborales típicamente masculinos.

El tercer apartado, escrito por la propia Elena Hernández y titulado El poder ambidiestro del lenguaje: género, injuria y sexualidad en 'La jarca de la universidad'de Rosario de Acuña, 1911, describe el caso de la escritora Rosario de Acuña y el forzoso exilio al que tuvo que someterse después de haber declarado que los estudiantes universitarios eran poco viriles al no querer que las mujeres entraran en 
la universidad pública española. Aunque nacida en la burguesía acomodada y con convicciones cristianas no practicantes, Rosario de Acuña se caracterizó por su carácter fuerte, por su no maternidad y por su cercanía a grupos socialistas y republicanos. Estaba convencida de la necesidad de que las mujeres accedieran a una educación igualitaria con los hombres, al tiempo que consideraba que la maternidad era esencial en la existencia de las mujeres, aun cuando ella nunca fue madre. Su carrera estuvo permeada por la polémica, en la que sus declaraciones y su estilo de vida le valieron acusaciones de brujería. Sus afirmaciones contra los estudiantes universitarios, de todas maneras, fueron las que la llevarían al ocaso de su vida pública, por la virulencia de la réplica, no solo por parte de los mismos estudiantes sino del gobierno español, que quiso llevarla presa. La figura de Rosario de Acuña representa, entonces, el trasegar de las mujeres de los últimos años del siglo XIX, cuando cualquier error o pisada en falso podría significar su destierro y su persecución social y legal.

Paralelo al caso de Rosario de Acuña, Pedro Ochoa, encargado del cuarto capítulo del libro titulado El desequilibrio universal no mengua: Sofia Casanova ante el espacio público en la década de 1920, relata la historia de la periodista Sofía Casanova, quien, como hija de su tiempo, fue cercana al nacionalismo, al feminismo y a la maternidad. Sofía Casanova, que vio de cerca los principales acontecimientos políticos de la Europa de la primera mitad del siglo XX, consideraba que la educación era esencial para la construcción de la Nación española, en la que la familia era su núcleo fundamental. Este principio nacionalista que cubrió su ideario político la llevó a entender a las mujeres como naturalmente dispuestas para la maternidad, aunque ella no lo fuera, y al feminismo como una tendencia aceptable, en cuanto promoviera la maternidad, el cuidado y la reproducción como rasgos propios del destino femenino. La familia nuclear, entonces, era para Sofía Casanova el espacio en donde los hombres y las mujeres podían desarrollar sus deberes frente a la Nación y a la Patria. Esta necesidad de conservar la Nación española hizo que Casanova fuera reticente al comunismo y al socialismo, por lo que vio en las mujeres un instrumento de contención frente a este fantasma, para ella tan amenazante: además de madres, todas las mujeres, especialmente las más pudientes, debían ejercer la caridad cristiana como manera de contener la pobreza y así evitar que el comunismo tocara a la puerta de España. Sofía Casanova fue, por tanto, un ejemplo del cambio que se fue dando durante los primeros años del siglo XX y de cómo las ideas van anteponiéndose unas a otras.

El quinto capítulo, titulado 'Historias de la radio’. Voces y estereotipos de mujer en la España de la década de 1950 y escrito por José Pérez, toma como referencia el programa radial 'Historias de la radio' para mostrar cómo la radio fue uno de los medios de comunicación más importantes de España durante las primeras décadas del siglo XX y el trascendental rol que tuvieron las mujeres en su consolidación, a pesar de los estereotipos reinantes: con la llegada de la radio comercial, las mujeres fueron contratadas con el ánimo de atraer compradores. Además, como reinas y ángeles del hogar, las mujeres fueron entendidas como espectadoras de primer nivel, al estar siempre en sus casas, por lo que buena parte de la comercialización radial y los programas de entretenimiento fueron hechos para mujeres. La consolidación del franquismo eliminó cualquier posibilidad de que las mujeres estuvieran presentes en espacios políticos y económicos, algo que se reflejó también en la radio, aunque esto no significó su ausencia total. La radio, por tanto, fue uno de los espacios más importantes de consolidación de la presencia de mujeres en contextos masivos, lo cual supuso un cambio sin precedentes en su camino por conquistar los espacios públicos.

Los capítulos sexto, séptimo y octavo se concentran en experiencias del Antiguo Régimen. El primero, escrito por Antonio Calvo, y titulado ' $E l$ desagrado de vuestra majestad hacia mi persona': la primera caída en desgracia del Conde de Aranda ante María Luisa de Parma (1789 - 1790), describe las relaciones de poder que se daban y tejían entre la nobleza y la reina de la monarquía hispánica del siglo XVIII. El caso del conde Arana es una representación de esas relaciones, en las que el desprecio de la reina significaba, con mucha probabilidad, la pérdida de influencia y de presencia, incluso física, en la corte, lo cual menguaba indiscutiblemente la carrera política del noble despreciado. Este estudio 
de caso supone una mirada de las relaciones de género más amplia, en la que el poder posee un rol diferenciador y las consecuencias del ejercicio de ese poder recaen de manera diferente sobre los sujetos, de acuerdo con las ventajas o desventajas que posean en el juego del ejercicio mismo del poder en sí mismos y en los otros.

En Discurso y práctica de la maternidad en dos mujeres en el Antiguo Régimen: Marie Jeanne Roland y Mary Wollstonecraft, de Tania Robles, se expone que la maternidad en el siglo XVIII era concebida como un acto patriótico, del que dependía la (deseada) ciudadanía femenina. Ser madre era trabajar por el fortalecimiento de la patria, razón por la que la maternidad era destino femenino. La 'madre republicana' se convirtió en la figura de ese destino y se concibió a todas las mujeres que habían rechazado la maternidad a lo largo de la historia como individuos a ser superadas, rechazadas e invisibilizadas. Las mujeres y madres republicanas del siglo XVIII debían educarse para la crianza de los hijos y no para otros menesteres, como el conocimiento o las luchas sociales. En ese contexto, las figuras de Marie Jeanne Roland y Mary Wollstonecraft son muy relevantes: ambas sujetas de relevancia política y social se ajustaban a la tendencia de amamantar por sí mismas a sus hijos, en una época en la que las nodrizas estaban perdiendo popularidad. Pero, mientras Wollstonecraft creía que la libertad de las mujeres estaba por encima de cualquier consideración o cualidad atribuida sobre sus cuerpos y que era esa libertad la que le permitía decidir sobre la maternidad, Roland pensaba que la maternidad era la base de la condición de la mujer y que las demás cualidades se desprendían de ella. Dos posturas que vislumbran las tendencias de los grupos y del feminismo que se desarrolló en los siguientes siglos, en un proceso amplio de cambios y permanencias.

El apartado de María Dolores Herrero, titulado ¿Una aguja en un pajar? En torno a un caso de divorcio en los archivos militares, ilustra el caso de doña Francisca Barba Osorio, marquesa de Castrofuerte, una noble adinerada casada con un militar durante el Antiguo Régimen. Las dinámicas matrimoniales del sistema castrense dieciochesco exigían una serie de requisitos que terminaron por generar una endogamia social dentro de la institución, en cuanto los militares y sus hijos e hijas terminaban conformando enlaces matrimoniales con otros militares y sus hijos e hijas. Esto fortalecía las conexiones sociales entre la milicia y, sobre todo, hacía más complejo cualquier posibilidad de romper con la normatividad. Por eso, el caso de la marquesa Barba Osorio merece atención: su matrimonio con un militar se realizó dentro de una relación desigual en la que ella poseía medios económicos y políticos mucho más grandes que su marido, razón por la que, al sentirse emocionalmente alejada de este después de mucho tiempo de casados, decidió dejar en su testamento su herencia a sus hermanas, aunque la tradición marcara que esta debía ir para el cónyuge. Además, fue de las pocas mujeres que pidió el divorcio durante esta época y lo llevó hasta la institucionalidad castrense, lo cual significó no solo la separación de los cuerpos, sino también la aplicación de la normatividad militar frente a la separación legal. Al igual que el capítulo sexto del libro, este apartado muestra las dinámicas del poder y cómo su ejercicio se convierte en una problemática situada en las relaciones de género, dentro de lo económico, lo político y lo legal.

El último capítulo, escrito por Paula Martos, y titulado La desintegración de lo público y lo privado en el espacio biopolítico: una mirada de género a partir del campo de concentración de Bergen-Belsen, se adentra en uno de los episodios más oscuros de la historia humana. En los campos de concentración nazi, los seres humanos pierden su individualidad, pierden la posibilidad de ser sujetos con cuerpos privados e íntimos. Los campos de concentración nazi son espacios políticos en los que la privacidad y la intimidad pasan a ser políticamente públicas. Es por eso que en estos lugares el género y la sexualidad pierden el carácter que la modernidad occidental les otorgó y pasan a los espacios públicos. Los cuerpos de los sujetos dentro de los campos de exterminio nazi pierden, por tanto, su sexualización y su sexualidad. Se genera un proceso de deshumanización que conduce, al tiempo, a una desexualización de los comportamientos. En ese punto, el nazismo elimina cualquier posibilidad de control de los sujetos, especialmente de las mujeres, de su propio ser corporal. El totalitarismo se adueña de los cuerpos y niega a los individuos el último y 
más cercano espacio de libertad: el propio cuerpo. Esto significa, en realidad, un logro de la modernidad occidental: el control biológico, social y emocional de los cuerpos, su disciplinamiento total.

Aunque los capítulos del libro parecieran no tener un hilo conductor evidente por la variedad de temáticas - lo cual haría un poco desordenada su exposición-, lo cierto es que los primeros cuatro capítulos se centran en exponer casos en los que las mujeres, como parte de grupos amplios o como sujetas y agentes sociales individuales, desarrollaron pensamientos, posturas y proyecciones durante el fin del siglo XIX y la primera mitad del siglo XX, a diferencia de los siguientes tres capítulos, los cuales parten de las coyunturas y los procesos históricos de género desde el siglo XVIII, pero, sobre todo, del Antiguo Régimen español y europeo. Esto permite conocer $\mathrm{y}$, tal vez, comparar los cambios y las permanencias temporales, por medio de estudios de caso, de diferentes aspectos sobre el ser mujer en relación con los espacios públicos y privados, especialmente sobre cuestiones como la maternidad, el rol de las mujeres ante la Patria y la Nación y la configuración de sus cuerpos frente a lo político, lo económico y lo social. El último capítulo, en cambio, es un rompimiento temático dentro del libro, en cuanto el régimen nazi inserta a las mujeres y a los sujetos en un todo, en los espacios públicos para eliminarles su humanidad y controlarlos hasta su desaparición.

De esta manera, Espacio público y espacio privado. Miradas sobre el sexo y el género es un libro con un abordaje amplio, en el que el uso de las experiencias de vida y de los estudios de caso permiten comprender aspectos históricos mucho más densos, al tiempo que logra, a pesar de ser un compendio extenso, mantener en los/as lectores/as la atención, pues los datos experienciales se compaginan con unas posturas concretas y estructurales sobre las mujeres en los espacios públicos y privados y se adentra en comprender cómo las sujetas que hacen parte de estos espacios no lo hacen como meras marionetas de un sistema que las domina y las hace actuar de una forma determinada, sino que, a pesar de los condicionamientos de sus contextos vivenciales, poseen un rol claro y reconocible como agentes sociales, aspecto indispensable para conocer de mejor manera las dinámicas sociales que envuelven las relaciones de género y que han determinado los espacios de las mujeres en España y Europa, aun durante las etapas más perversas del trasegar humano en el planeta.

\section{Referencias bibliográficas}

Hernández, Elena. (Ed.). (2016). Espacio público y espacio privado. Miradas desde el sexo y el género. Madrid, España: Abada Editores. 